LIAMES, Campinas, SP, v. 19, 1-25, e019002, 2019

\title{
Cuestiones etimológicas del alma originaria
}

\author{
Erik Cajavilca Veramendi \\ Universidad Nacional Mayor de San Marcos, Lima-Perú \\ https://orcid.org/0000-0003-0274-9616
}

\begin{abstract}
The word that evokes soul in indigenous or traditional societies is conceptually more complex, richer and with more uses than the discreet Christian soul. In this sense, the article addresses the soul of traditional societies from an etymological approach in order to fill some gaps about its nature, but tracing the routes already covered by ethnography. The etymological study shows that the term that denotes soul or invisible principle has been derived from a limited number of basic words that can be organized into two categories: the first class has produced a body soul and the second, a free soul. Starting from both the ethnographic information and that classification scheme, the original meaning of the yoshi term of the pano languages of the Amazon has been proposed. Consequently, it has been found that yoshi is etymologically linked to the free soul from an ancient idea that involved certain nocturnal, quite feared and respected animals.
\end{abstract}

KEYWORDS: Body soul; Free soul; Pano languages; Etymology; Linguistic anthropology.

RESUMEN: A palavra que evoca alma nas sociedades indígenas ou tradicionais é conceitualmente mais complexa mais diversa e com mais usos que a discreta alma cristã. Nesse sentido, com o fim de encher alguns vazios com respeito a sua natureza, o artigo aborda a alma das sociedades tradicionais desde um enfoque etimológico, mas traçando as rotas já percorridas pela etnografía. O estudo etimológico mostra que o termo que denota alma ou princípio invisível derivou-se de um número limitado de palavras básicas que podem ser organizadas em duas classes. A primeira classe tem produzido uma alma corporal e a segunda, uma alma livre. Partindo tanto da informação etnográfica como daquele esquema clasificatorio, se propôs o significado original do termo yoshi das línguas pano da Amazonía. Encontrou-se que yoshi está etimologicamente vinculado à alma livre a partir de uma ideia antiga que envolvia a certos animais noturnos muito temidos e respeitados.

PALAVRaS-CHAVE: Alma do corpo; Alma livre; Línguas Pano; Etimologia; Antropologia linguística.

\section{Introducción}

Todas las sociedades, antiguas y actuales, tienen una palabra para alma; no obtante, algunas sociedades todavía mantienen ideas originales del alma que abarcan otros sentidos que aquel atribuido, en la actualidad, por el alma cristiana y que va a producir una incomprensión en el hombre occidental. En síntesis, el alma originaria fue el concepto creado para explicar las funciones o los efectos atribuidos hoy a la respiración celular, a los agentes infecciosos, a las toxinas del aire, ${ }^{1}$ a facultades cognitivas, pero incluso

${ }^{1}$ Entiéndase que aquí no estoy atribuyendo saberes científicos a los hombres de sociedades tradicionales, sino simplemente considero que tanto el hombre de una sociedad premoderna como el de una sociedad moderna razonan de la misma manera, si bien hay diferencias en el objeto de estudio. 
también para explicar asuntos que competen a los estados alterados de la conciencia y al plano del inconsciente. En ese sentido, es posible hablar no de un alma, sino de muchas almas que componen el ser humano en particular y el «ser vivo» en general. Así, para dar solo un ejemplo, en la Amazonía se habla de una entidad invisible que vitaliza el cuerpo, da sostenimiento a la carne y que no debe compartir su sede con ninguna otra entidad invisible intrusa; ¿acaso no es este un mecanismo parecido al de los agentes infecciosos que invaden nuestro organismo provocando un desequilibrio químico a nivel celular? agentes que, al igual que los nativos, nosotros tampoco podemos ver a simple vista. Actualmente, en el mundo occidental, el alma es vista solo como algún aspecto de la identidad, ya que se le emplea como una extensión de la misma después de la muerte, pero sin el cuerpo.

Son las sociedades tradicionales quienes emplean este esquema complejo del alma adoptado en una o más palabras y que los investigadores occidentales traducen como 'alma', 'soul' o simplemente dejan los términos originales sin traducir y hacen una descripción ontológica de las categorías. Solo el antropólogo es capaz de develar en cierta medida en qué consiste el alma, no obstante, incluso con ayuda de la disciplina antropológica, el alma originaria puede verse oscura y mal comprendida en ciertos casos, más aún, la aculturación y la extinción de las lenguas van a impedir una descripción completa. Ante estos inconvenientes, la lingüística, a través de la terminología comparativa, podría iluminar un poco más respecto a la noción original de alma.

Uno de estos términos es yoshi de los pueblos de lenguas pano y considerado generalmente como el alma o principio invisible que compone al ser vivo. El objetivo de este artículo es, por consiguiente, descubrir lo que subyace al concepto de yoshi, no solo en el aspecto etnológico, sino también desde el punto de vista lingüístico. Se demuestra que las bases semánticas del concepto de alma efectivamente son aquellas palabras que describen aspectos acerca de la vida, el cuerpo, el crecimiento, la conciencia, el inconsciente, entre otros similares. Todas estas ideas acerca del alma original pueden resumirse siguiendo la descripción hecha por Hultkrantz (1979) acerca de dos tipos generales de alma: el alma corporal y el alma libre. Precisamente, en la actualidad, todavía existen representantes de cada tipo en las sociedades tradicionales y que la tradición cristiana se ha ocupado de enfrentarlos y de situarlos entre dos polos opuestos; el desprecio por el alma libre llegó a tal punto que muchos de los términos nativos han sido traducidos como 'demonio' por los misioneros. Fuera de esta visión limitada de occidente, los dos tipos de almas no son necesariamente antagónicos, sino son muchas veces compatibles e influyentes entre sí.

El artículo se organiza de la siguiente manera. La segunda sección desarrolla de forma resumida algunas de las bases semánticas de alma; es decir, las palabras que habrían derivado el concepto de alma, ordenadas a su vez en dos casos generales. La tercera sección presenta la propuesta etimológica para el término yoshi de los pueblos pano de la Amazonía. Los resultados muestran que el término está vinculado indirectamente a la tipología del alma libre y se comprueba, además, la importancia de la idea del ente extraño y misterioso en un plano tanto psicológico como social.

En adelante, siempre que se mencione alma, me estaré refiriendo al alma de las sociedades tradicionales (antiguas y actuales), salvo que tenga que referirme al alma cristiana, esta será especificada cada vez que lo mencione. La mayoría de protoformas que aparecen en este artículo e identificadas con * han sido obtenidas de la tesis de Oliveira (2014). 


\section{Sobre conceptos y origen de la palabra: el alma originaria}

Lo primero que llama la atención respecto al alma de los amerindios es que esta es una entidad implantada en la vida cotidiana de las personas. Hablar de alma es tan común para ellos, como nosotros, los de Occidente, hablamos de dinero, vestimenta o las llaves de la casa; por lo tanto, desde su punto de vista, el alma es algo objetivo porque pueden sentirla. Es parecido a lo que nosotros entendemos por electricidad: es algo que no podemos ver, pero sabemos que existe, incluso percibimos sus efectos. El alma tiene autonomía, se desprende del cuerpo en ciertos momentos; también permite el funcionamiento orgánico del cuerpo, y hace posible la conciencia. Lo siguiente que llama la atención es que el alma no está solo «en» los seres humanos, sino también en otros seres del mundo (incluyendo las cosas); por otro lado, un solo ser puede poseer no solo una, sino múltiples tipos de almas.

En la medida que no tengamos en cuenta todos estos aspectos, el alma amerindia seguirá siendo oscura para el neófito. El problema conceptual radica en la brecha que separa nuestra concepción drásticamente dualista que nos impide ver lo que hay en el fondo, o no ver las complejas redes contextuales alrededor del «alma». Por supuesto que, si la sociedad está aculturada, no habrá inconvenientes en ver al alma como un reflejo del alma cristiana, pero si estamos ante una sociedad firme, que ha conservado lo mejor posible su pureza cultural, el original rostro del alma solo podrá ser comprendido en la medida que uno llegue a convivir y compartir con la cultura originaria, así como lo hacen los etnógrafos. No obstante, la etnografía podría servirse a su vez de la lingüística, y es que esta disciplina podría mostrarnos o, en todo caso, comprobar lo que se describe en la etnografía. En efecto, el estudio de las palabras nos revela que conceptos estrictamente culturales se han originado a partir de conceptos que refieren a objetos físicos objetivos; sin embargo, el proceso no es arbitrario, sino está motivado por algún esquema mental que organiza el mundo, por la cosmovisión de una sociedad. Excavar hasta el fondo de la palabra podría darnos una visión de esta forma de organizar el mundo.

A partir de los estudios etnográficos se puede inferir que el concepto de alma ha llegado a articularse por la confluencia de dos planos conceptuales. Así, tenemos que los elementos concretos que han servido para la formación del concepto de alma son típicamente de dos tipos: todo lo que tenga que ver con el estar vivo, el movimiento y la intencionalidad y, por otro lado, todo lo relacionado a la sombra o imagen. Veamos cada una de estas dos clases.

La primera clase corresponde a la sustancia que se cree hace posible la vida y que ha sido interpretado muchas veces con el aire que entra o sale del cuerpo. Observe que, en la antigua Europa, el término que indica alma también significa aliento, aire, respiración. La palabra castellana alma es un derivado del latín anima, ${ }^{2}$ término reportado desde el siglo III a. C. y usado para referirse a una especie de alma-aliento. La imagen que tenemos de anıma de los romanos es comprendida a partir de los relatos sobre el moribundo que

${ }^{2}$ Consúltese alma (del latín anima 'aire', 'aliento', 'alma') en el diccionario etimológico de Corominas (1987: 42). El latín anĭma (primera declinación) fue derivado a su vez de ănümus (segunda declinación). Con este cambio, los antiguos romanos pudieron distinguir entre un alma vital y un alma del razonamiento o voluntad (cf. Lewis 1984: 121).

LIAMES, Campinas, SP, v. 19, 1-25, e019002, 2019 
exhalaba el último suspiro y cuya «alma se escapaba por la boca» (cf. Blázquez, MartínezPinna y Montero 2011: 520; Hope 2007: 94; Bayet 1984: 239). La $\psi \bar{v} \chi \dot{\eta}$ (psyché) ${ }^{3}$ griega, derivado del verbo $\psi \bar{v} \chi \omega$ 'soplar', 'respirar' (cf. Beekes 2010: 1672) es rastreada desde tiempos homéricos (VIII a. C.).

En su libro sobre el alma griega, Rohde (1948: 9) describe una figura parecida al anı̈ma latina que sale por la boca: «Su nombre [psique], al igual que la palabra "alma" que recibe en las lenguas de muchos otros pueblos, nos la presenta como algo aéreo, etéreo, como un hálito de vida que se escapa del cuerpo con el último aliento. Sale de él por la boca y también, sin duda, por la herida abierta del agonizante y, una vez libre, recibe también el nombre de "ídolo" (eidolon), imagen». Se sabe también que los antiguos pueblos iranios ya manejaban el concepto «alma-aliento». Por ejemplo, en el antiguo avéstico $\left(2^{\circ}\right.$ milenio a. C.), encontramos que el hombre es un cuerpo constituido por diversos componentes tanto materiales como inmateriales; entre estos componentes están el ushtāna 'aliento de vida', el anma 'aliento' y el urwan 'alma(-aliento)' (cf. Daryaee 2012: 78), claramente vinculados por el mismo campo semántico, aunque diferenciados por un discurso rico en especificidad. El mismo término ănı̆mus sería una herencia indoeuropea: ănŭmus es cognado con el griego $\alpha$ ṽ $\varepsilon \mu \varsigma_{\varsigma}$ 'viento', cuya raíz es compartida por otras lenguas de la antigüedad, así tenemos, en el sánscrito, an 'respirar', anas 'aliento', anilas 'viento'; en el gótico, uz-ana 'exhalar'; en el gaélico escocés, anal 'aliento' (cf. Lewis 1984: 123); en la familia hamito-semítica *naf 'aliento' (cf. Orel \& Stolbova 1995: 395); en harari, näfaha 'inflar', 'soplar' (cf. Leslau 1963: 117). En el diccionario etimológico de Michiel de Vaan (2008: 43), encontramos la forma protoitálica *anamo- con el significado de ‘aliento' o 'espíritu' y el protoindoeuropeo * $h_{2}$ enh $h_{1}$-mo- 'aliento'.

La vida también está vinculada al nacimiento, a la primavera, a la luz solar que baña con sus tibios rayos y que hace posible los brotes vegetales. Un ejemplo representativo es el alma de los nahuas que era en realidad una pluralidad de almas: tonalli, teyolia e ihiyotl. El primero, tonalli, era como un principio vital que hacía posible el crecimiento y el pensamiento. López (2004: 233) dice que «era una fuerza que determinaba el grado del valor anímico del individuo» cuyo centro era el corazón, aunque también se dice que era el hígado o la sangre (ibíd.: 234). Se deriva de la raíz verbal tona 'hacer calor', 'haber sol' y que ha dado lugar a palabras como tonacayotl 'productos de la tierra'; tonacati 'ser abundante', 'fertil'; tonalcayotl 'relativo al verano' (cf. Siméon 1992: 715). El teyolia, tradicionalmente centrado en el corazón, involucraba la vitalidad, el conocimiento y los afectos (cf. López 2004: 254-255). Se deriva de la raíz yoli 'nacer', 'abrirse las flores' (cf. Siméon 1992: 195). El ihiyotl, el alma de la apetencia y las pasiones, en cambio, se deriva de la raíz ihio- 'aliento', 'soplo', 'respiración', 'aire', 'saliva' (ibíd.: 183), de allí que el ihiyotl era concebido como gas o emanación del hígado. Ahora bien, como hemos visto, a estos tipos de almas se les atribuye una sede en alguna parte del cuerpo; es decir, los órganos del cuerpo fueron considerados contenedores de alma; esto motivó posteriormente, a través de un proceso metonímico, que el término que indica algún órgano pase a señalar directamente al alma. Por ejemplo, en el diccionario etimológico hamito-semítico (cf. Orel \& Stolbova 1995) hay un vínculo filológico entre alma y la raíz *kabul 'corazón', 'estómago'. En el diccionario etimológico del viejo chino (cf. Schuessler 2007), entre

\footnotetext{
${ }^{3}$ Psyché significa literalmente 'yo soplo' (cf. Onians 2000: 93).
} 
alma y хиè ‘sangre', 'médula'. Según Weiss (1972: 171), el término asháninka ${ }^{4}$ nasánkane significa tanto 'corazón' como 'alma'; es decir, el contenedor del alma ha llegado señalar al alma misma. ${ }^{5}$ En principio, el tipo de alma vinculado a las partes corporales no se despega, sino está fija en el cuerpo mientras la persona está viva -aunque esto es relativo.

La segunda clase involucra cualquier forma que aparezca como un doble de nosotros mismos, de allí que la sombra del cuerpo, la imagen reflejada o la imagen de los sueños son consideradas almas. La concepción del doble es un tipo de conciencia del Self. Consiste en reconocer mi Self fuera de mí mismo. Los sueños han tenido un papel importante en la evolución de la noción del doble, llegando a reconocer la existencia de una persona en nuestro interior o mundo paralelo y que tiene actividad propia (cf. Zusne \& Jones 2014: 129). Aquella persona con nuestro rostro o apariencia similar es nuestro alter ego, como también fue reconocido la sombra corporal, el reflejo o las imágenes delirantes. En psicoanálisis, el fenómeno del doble se conoce como «autoscopía» y es considerado una anomalía mental, aunque algunos son más cautos al respecto:

\begin{abstract}
La autoscopia emerge, tal vez, como un fenómeno curiosamente menos raro de lo que hasta ahora ha sido pensado. Cuando nos detenemos a considerarlo con más cuidado, podemos encontrar rápidamente evidencia diaria de sus ocurrencias en los sueños, donde el Self observador mira desinteresadamente a un Self que actúa o participa. Si tuviéramos que ampliar la definición de autoscopia para incluir fenómenos ultrasensitivos como fantasías (experiencias intrapsíquicas), podríamos decir entonces que los fenómenos autoscópicos incluyen todo el espectro de la conciencia del Self, de "normal" a "anormal". La "banda sensitiva" (visual, cinestésica y auditiva) de autoscopia propiamente dicha se ubicaría en una posición de este espectro. (Friedmann \& Faguet 1982: 73 [traducción mía])
\end{abstract}

En casos culturales específicos, las personas son capaces de percibir su doble en objetos concretos tales como personas, animales, cosas; en objetos figurados, seres invisibles o fantasmas. Para los antropólogos, el doble no sería más que una introyección ${ }^{6}$ del ser ausente en el que se produce una relación entre la persona y la imagen reificada. Por lo tanto, es la separación o la nostalgia lo que lo hace real a la mente (cf. Viveiros de Castro 1986: 498; Vilaça 1992: 55; Vernant 2006: 325).

Como ejemplo, los antiguos griegos consideraban que el alma ( $p$ sique) se transformaba en eidolon 'imagen' y en skia 'sombra' para subsistir en el reino de Hades después de la muerte (cf. Rohde 1948: 9; Onians 2000: 93-95). Eidolon es la forma nominal del verbo $\varepsilon i \delta o \mu \alpha l$ 'aparecer', 'parecerse' y este vendría de la raíz verbal indoeuropea *ueid-

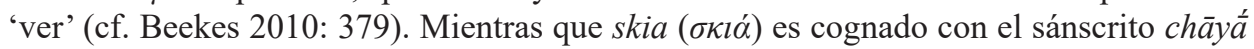
'sombra', 'imagen', 'reflejo, 'parecido'; con el avéstico a-saiia- 'aquel sin sombra'; con el

${ }^{4}$ Weiss, en su obra Campa Cosmology (1975), aborda la cosmología de los asháninka de las riberas del Apurímac, Ene y Tambo.

${ }^{5}$ No es el caso con noshire, que tiene el mismo doble significado, ya que no hay evidencia de que la raíz -shire haya indicado antiguamente a algún órgano corporal. Más bien, el sentido de 'corazón' es una adición reciente.

${ }^{6}$ En Galimberti (2002: 632-633), el concepto introyección se define así: «Proceso con el que se incorpora en el sistema del yo la representación mental de un objeto externo, por lo que la relación del yo con el objeto se transforma en la relación del yo con la imagen del objeto introyectado». Consúltese también en Neumann (1989: 204, 352).

LIAMES, Campinas, SP, v. 19, 1-25, e019002, 2019 


\title{
CAJAVILCA - CUESTIONES ETIMOLÓGICAS DEL ALMA ORIGINARIA
}

moderno persa sāya 'sombra', entre otros y vendría del indoeuropeo *skeh $-i h_{2}$ 'sombra' (ibíd.: 1350-51). Alma en lengua manchú se dice faijə (fajayGa en manchú literario) y se ha propuesto una relación de cognados entre otras lenguas manchú-tunguses con el significado de 'sombra', p. ej.: hańan (evenki), hịnān (even), xańan (negidal), pańa(n) (ulcha), pana(n) (orok), lo que resultaría la protoforma manchú-tungús *pańa-n 'sombra' (cf. Starostin; Dybo; Mudrak 2003: 1078). En el guaraní misionero, el término ang denota 'alma', 'espíritu', 'conciencia', claramente derivado de ãng 'sombra', 'abrigo'. De ãng se deriva taãngába 'imagen' y también ñẽangechacába 'espejo', el cual esta formada por el reflexivo ñe-, el nombre ãng 'sombra', el verbo echag 'mirar' y el nominalizador -hába (lit. 'lo que sirve para mirarse la sombra') (cf. Ruiz de Montoya 1876). Weiss sugiere que el significado original del alma asháninka, -šire, no sería el órgano del corazón, sino algún concepto vinculado a la raíz verbal -ši- 'parecerse' (1975: 428). Esto se verifica en los diccionarios; por ejemplo, el adjetivo asháninka shiirori 'similar', 'parecido' (cf. Kindberg 1980); la raíz verbal ashéninka -shi-7 'parecerse', 'asemejarse' (cf. Payne 1980). Los shipibos tienen el término caya que denota 'sombra' y 'alma', cuyo significado original habría estado vinculado efectivamente a la sombra y posición del sol (véase $\S 2.3$ ).

Para resumir, en este segundo caso, los conceptos objetivos pertenecen al espacio semántico que incluye lo siguiente: sombra, imagen, reflejo, doble, otro, semejante, parecido o parecerse, $y$, actualmente, para referirse también a fotografía. Se cree que este tipo de alma tiene libertad de desplazamiento y no necesita involucrarse fijamente con un órgano. En teoría, el alma libre no debería tener asiento corporal, en todo caso, su localización en el cuerpo es indeterminada:

\begin{abstract}
El alma libre, por tanto, se encuentra siempre activa fuera del cuerpo; no está ligada a éste como las almas del cuerpo. Pero, precisamente porque el alma libre opera fuera del cuerpo, su ubicación en el interior de éste resulta bastante oscura, sobre todo porque, cuando su dueño está despierto, el cuerpo representa al individuo y sólo sus actividades tienen interés. [...] Su exacta localización en el cuerpo es, por tanto, un asunto de importancia menor, si bien es un tema que suscita frecuentes debates. (Bremmer 2002: 27-28)
\end{abstract}

Esta doble dimensión, descrita en los dos casos abordados, es un aspecto del alma que ya Hultkrantz (1979: 131) había advertido con respecto a los nativos norteamericanos: «En toda América del Norte, excepto en el suroeste, se repite la creencia, de una u otra forma, de que el hombre está equipado con dos tipos de alma: una o más almas corporales que otorgan vida, movimiento y conciencia al cuerpo, y un alma libre o del sueño idéntica al hombre mismo cuando se manifiesta fuera de su cuerpo en varias zonas psíquicas crepusculares». Esta teoría se podría extender a todas las sociedades tradicionales en general. ${ }^{8}$ La doble tipología de almas puede servir como una referencia teórica. Sin embargo, en la práctica encontramos intersecciones y matices; es decir, un alma que tiene sede en el corazón puede también ser un alma libre y, por lo tanto, salir del cuerpo en estados inconscientes. Dependiendo de las circunstancias y esquemas culturales de cada

\footnotetext{
${ }^{7}$ Encuéntrase con el lema oshiyaantsi 'parecerse', 'asemejarse', en el cual $o$ - es un morfema pronominal fosilizado y -aantsi es la terminación verbal no finita.

${ }^{8}$ Todas las sociedades tradicionales pueden potencialmente tener estos dos tipos de alma. Si hay un pueblo que tiene solo uno de ellos o ambos es solo contingente.
} 
pueblo, el sistema de conocimientos puede variar; algunas veces los conocimientos se superponen o se amplifican, otras veces dejan de ser importantes y quedan en segundo plano, todo esto se refleja en el léxico.

Hay pueblos que tienen términos tanto para las almas corporales como para el alma libre; otros, solo para almas corporales con capacidad de liberarse; otros, en cambio, articulan a un alma libre sin sede conocida. En todo caso, un solo concepto de alma podría abarcar todas las propiedades, -siendo a la vez un alma libre con asiento corporal.

Como el conocimiento y los conceptos ancestrales de las sociedades sin escritura no son fijados dogmáticamente, no es extraño encontrar términos con significados superpuestos, sumado al hecho de que, en su desarrollo normal, las palabras van a extender nuevos vínculos semánticos. Todo esto produce, por un lado, el enriquecimiento del concepto de alma — insertado en una cosmología particular y compleja - y, por otro lado, en ocasiones dificulta una definición precisa del alma amerindia. Así, por ejemplo, la entidad anímica de los antiguos nahuas, el ihiyotl, según el diccionario de Simeón (1992), significa 'aliento', 'aire', no obstante, estaba vinculado al hígado (cf. López 2004: 262). El alma de los asháninka, nošire, tiene asiento en el corazón, pero es a la vez un alma libre que se desprende del cuerpo (cf. Weiss 1975: 427). El caya de los shipibos, a pesar de ser un alma-sombra o «el doble espiritual del cuerpo físico» está localizado específicamente en el cuerpo, entre el corazón y el diafragma (cf. Bertrand-Rousseau 1986: 106). El término achuar para alma, wakan, es descrito como «la sombra proyectada o el reflejo en el agua» (Descola 2005: 232), lo que sugiere pensar que el significado original de la palabra era sombra o imagen; sin embargo, el análisis comparativo no llega a confirmarlo. No hay evidencia de que wakan se haya derivado de sombra, imagen, vida, nacimiento, ni tampoco del nombre de algún órgano, más bien, wakan sería un préstamo de alguna lengua vecina que también estuvo en contacto con las lenguas cahuapanas de la zona; véase la siguiente raíz compartida entre dos lenguas cahuapanas: en chayahuita: hua'yan(ën) 'alma', 'espíritu', 'imagen', 'sombra'; hua'an 'jefe', 'cacique'; hua ’anën 'dueño' (cf. Hart 1988); en shiwilu: wa'dan 'espíritu', 'alma'; wa'an ‘jefe', ‘dueño’ (cf. Valenzuela 2013). Por lo tanto, el término wakan no sería originalmente achuar, su procedencia no ha sido esclarecida. Esto abre un nuevo aspecto de las dimensiones etimológicas de alma en el que estaría involucrado los conceptos de jefe, dueño y, por extensión, los conceptos de padre, anciano o antepasado.

En suma, los dos casos expuestos forman una tendencia hacia la formación de los conceptos. Por un lado, tenemos el espacio semántico de la «vida» (alma corporal) que incluye los conceptos de nacimiento, calor, aliento, aire, los nombres de órganos y fluidos; y, por otro lado, el espacio semántico de la «sombra» (alma libre) que incluye, a saber, la sombra, imagen (de los sueños), reflejo, doble, otro, semejante, imitación, parecido o parecerse. No obstante, debemos dejar abierta la posibilidad de otros subcampos como el de la «ancestría» y conceptos derivados: padre, abuelo, anciano, antepasado, jefe, dueño, en vista de la importancia del aspecto de la transmigración del alma, cuya concepción podría fomentar la creación de términos que denoten una especie de alma-ancestro. Esta dimensión de la «ancestría» se corresponde menos con el alma corporal y más con el alma libre. A partir de todo lo expuesto, a continuación, intentaremos justificar el origen del término yoshi de los pano de la Amazonía. 


\section{El alma en los pueblos pano: yoshi $^{9}$}

\subsection{Introducción al alma de los pano}

En las obras tanto etnográficas como lexicográficas, encontramos que los pueblos pano, ${ }^{10}$ especialmente de la Amazonía peruana, le dan importancia al alma de la sombra o imagen. Por un lado, expresado con el término que señala a la sombra misma y, por otro lado, expresado con un término general, yoshi, cuyo origen etimológico intentaremos descubrir. Este yoshi puede representar una pluralidad de almas; por ejemplo, los cashinahua emplean el término como núcleo de frase nominal para nombrar múltiples entidades que conforman su ser. Así, en teoría, es posible tener un yoshi para diversas partes del cuerpo (del ojo, del diente, de la sangre), para las excreciones (de la orina, de las heces, del sudor) y también para algún rasgo psicológico (yoshi de la nobleza o de la maldad). Además, la imagen de los sueños y la sombra del cuerpo son también yoshi (cf. Yano 2009: 71-72; Lagrou 1998: 85-86; Ribeiro 2014: 80-82).

Los yoshi más importantes son el alma del ojo, motivada por la imagen reflejada en el iris (p. ej., Yano (2009), cashinahua, bedu yuxin, ${ }^{11}$ lit. 'yuxin del ojo'), y el alma del cuerpo o sombra (ibíd., yuda baka yuxin, lit. 'yuxin de la sombra del cuerpo'); en algunos casos se «ahorra el esfuerzo» y solo se expresa yoshi para referirse a la sombra corporal. Como ya he mencionado, también se emplea el mismo término de la sombra concreta para referirse al alma del cuerpo, p. ej., cáya en shipibo y mayan en matsés. Los shipibos tienen hasta cuatro términos que denotan 'sombra': cáya, huéa, beí, óta (LOR), y tres de ellos connotan significados cosmológicos. Como afirma Bertrand-Rousseau (1986), incluyendo el alma del ojo, bëi, ota, bero yoshin y caya son tipos de almas. Ahora bien, este mismo criterio general, que otorga más importancia al alma del ojo y el alma del cuerpo (sombra), se evidencia en el vocabulario de los otros pueblos pano cuando se busca la traducción para 'alma' o 'espíritu' (véase el Cuadro 1).

¿Cómo es definido yoshi por la antropología? Bertrand-Rousseau (1986: 9495) explica que yoshi es lo otro, lo extraño, lo anormal, en ese sentido puede ser una especie animal, vegetal o no biológica. No tiene una sola apariencia, lo impregna todo y a él se le atribuye ser el causante de muchos males. Según Townsley (1993), para los yaminahua, yoshi señala a lo extraño, misterioso, a lo no conocido; asociado a la noche, a lo indistinguible y a los sueños. Los yoshi también van a permitir el normal desarrollo del cuerpo y son responsables de las enfermedades, los males y la muerte; esta dependencia es aprovechada por el chamán quien se encarga de restablecer la salud manipulando el yoshi. $\mathrm{Su}$ carácter errante es un defecto por el cual adquieren y transmiten los males de otros. Impregna toda la materia (biológica y no biológica) y aunque es un concepto difícil de

${ }^{9}$ Aquí transcribo una forma representativa de la palabra y es la que usaré en todo el artículo, salvo que tenga que referirme a una forma de un autor específico. Aparecen las siguientes formas en los diccionarios consultados: iôxĩ, iushi, yoshi(n), yuxi(n), ñunshin, chusin entre otras.

${ }^{10}$ Las lenguas pano son una familia lingüística amerindia que se hablan en la Amazonía oriental del Perú, en el noroeste de Bolivia y en los estados brasileños de Amazonas y Acre, próximos a la frontera peruana (cf. Dixon \& Aikhenvald 1999: 227-229).

${ }^{11}$ La grafía / $\mathrm{x} /$ representa (en todas las formas registradas en los diccionarios del Cuadro 1) al sonido fricativo postalveolar [š], también escrito como $/ \mathrm{sh} /$. 
explicar para los mismos yaminahua, ellos entienden que yoshi es constitutivo y a la vez autónomo (ibíd.: 452). En realidad, la ampliación del concepto de yoshi está en función de la categoría del ser. En estas circunstancias, el estudio del origen de las palabras viene como herramienta útil para intentar llenar algunos vacíos en la definición antropológica.

\subsection{Los diccionarios y el léxico}

A partir de catorce diccionarios bilingües de lenguas pano, he examinado aquellos términos reportados para 'alma' y conceptos relacionados (véase Cuadro 1). Los diccionarios han sido publicados desde principios del siglo $\mathrm{xx}$ hasta principios del siglo XXI. En adelante se señalará a los diccionarios con el nombre del autor de forma abreviada (véase las abreviaturas al final del documento).

Como se observa en el Cuadro 1, las traducciones más recurrentes para 'alma' son aquellas palabras que indican el alma del ojo (p. ej. LoR, béroyoshin). Asímismo, aunque menos frecuente, encontramos expresiones que indican la sombra y conceptos similares, como en matsés (mayan, 'alma', 'sombra', 'imagen', FLE), shipibo (cáya, 'alma', 'sombra', 'reflexión', LOR) y capanahua (caya' 'alma', LOO). El término yoshi, por sí solo, se emplea por lo general para indicar 'espíritu' o 'demonio'. Desde luego, no vamos a encontrar, en los diccionarios, referencia de todas las almas reportadas en las etnografías (alma del diente, de la orina, de la afectividad, etc.), sino solo las expresiones para alma más representativas.

Desde ya, la no ocurrencia de términos alusivos a los órganos, fluidos, aliento, aire o calor, en el Cuadro 1, indicaría que los términos yoshi y caya no guardan relación etimológica con conceptos básicos del alma corporal. Más bien todos los conceptos enunciados, en la primera columna, o pertenecen exclusivamente al espacio semántico del alma libre o son simplemente adaptaciones modernas. Por lo tanto, los datos están ordenados (separados con una línea gruesa) siguiendo un criterio general semántico de los conceptos: el primer grupo refiere al ser espiritual, el segundo a la sombra-imagen y el tercero al ancestro. En el cuadro, también, se exponen los términos que denotan ‘dueño' (*?i?ßo) para propósitos comparativos, asimismo los términos que denotan 'otro' (*wits $(a)$ ), solo para confirmar una improbable relación léxica con yoshi.

Como una aclaración pertinente, en pleno siglo XXI, la mayoría de los pueblos tradicionales ya se han «occidentalizado» ideológicamente, por lo que no se puede afirmar que actualmente sus términos locales conserven la idea original; sin embargo, apelando al análisis y comparación de diversos datos registrados en diccionarios bilingües, podemos rescatar algún esquema de pensamiento originario.

${ }^{12}$ En el diccionario capanahua de LOO, caya no hace referencia a 'sombra', tampoco 'imagen' o 'reflejo'; en su lugar, están hota, yoshin 'sombra', véase Cuadro 1. 


\begin{tabular}{|c|c|c|c|c|c|c|c|c|c|c|c|}
\hline 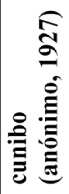 & 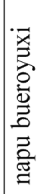 & $\mid$ & 莕 & 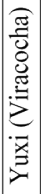 & 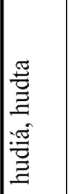 & | & 憩 & 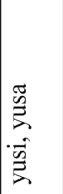 & 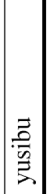 & 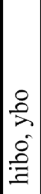 & 敢 \\
\hline 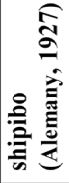 & 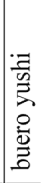 & | & 芯 & 1 & $\stackrel{\mathscr{\Xi}}{\Xi}$ & 1 & 兽 & $\overrightarrow{\underline{a}}$ & 1 & 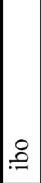 & 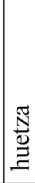 \\
\hline 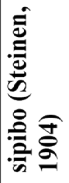 & 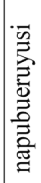 & | & $\overline{\mathrm{x}}$ & : & 嗂 & | & 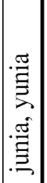 & 离 & 离 & 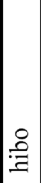 & 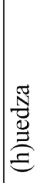 \\
\hline 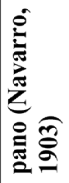 & 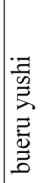 & 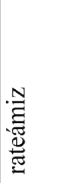 & $\begin{array}{l}\frac{\Xi}{\exists} \\
\frac{1}{5} \\
\frac{2}{5}\end{array}$ & 1 & 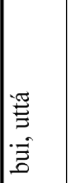 & | & 愛 & 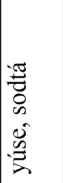 & 1 & $\therefore$ & 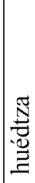 \\
\hline 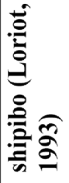 & 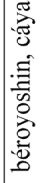 & 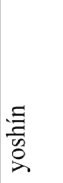 & 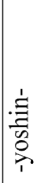 & 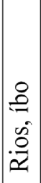 & 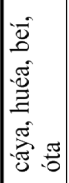 & 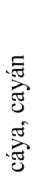 & 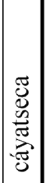 & 离 & 离 & : & 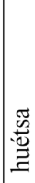 \\
\hline 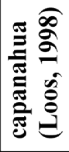 & 荧 & 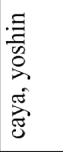 & 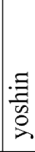 & 总 & 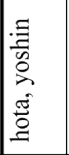 & I & 1 & 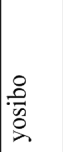 & 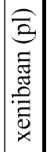 & 总 & 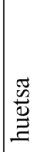 \\
\hline 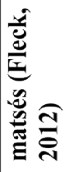 & 氶 & 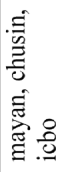 & 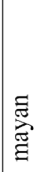 & : & 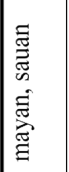 & 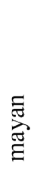 & | & 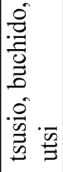 & 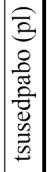 & $\begin{array}{l} \\
.8 \\
.0\end{array}$ & .5 \\
\hline$\frac{\tilde{n}}{\frac{3}{3}}$ & $\frac{\mathbb{E}}{\sigma}$ & 㷼 & 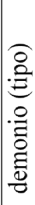 & 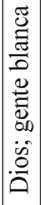 & 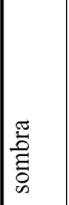 & 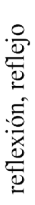 & 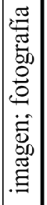 & 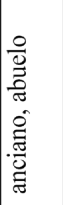 & 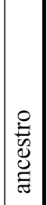 & & : \\
\hline
\end{tabular}

${ }^{13}$ Los vocabularios han sido publicados desde principios del siglo xx hasta principios del siglo XxI. En el cuadro se registra las revisiones de tres diccionarios shipibos, abordados por tres autores distintos (Steinen, Alemany y Loriot et al.) en un tiempo y espacio relativamente distintos. También dos diccionarios cashinahuas (Abreu y Montag). Los diccionarios están ordenados según la cercanía geográfica entre las lenguas. 
Continuación del Cuadro 1

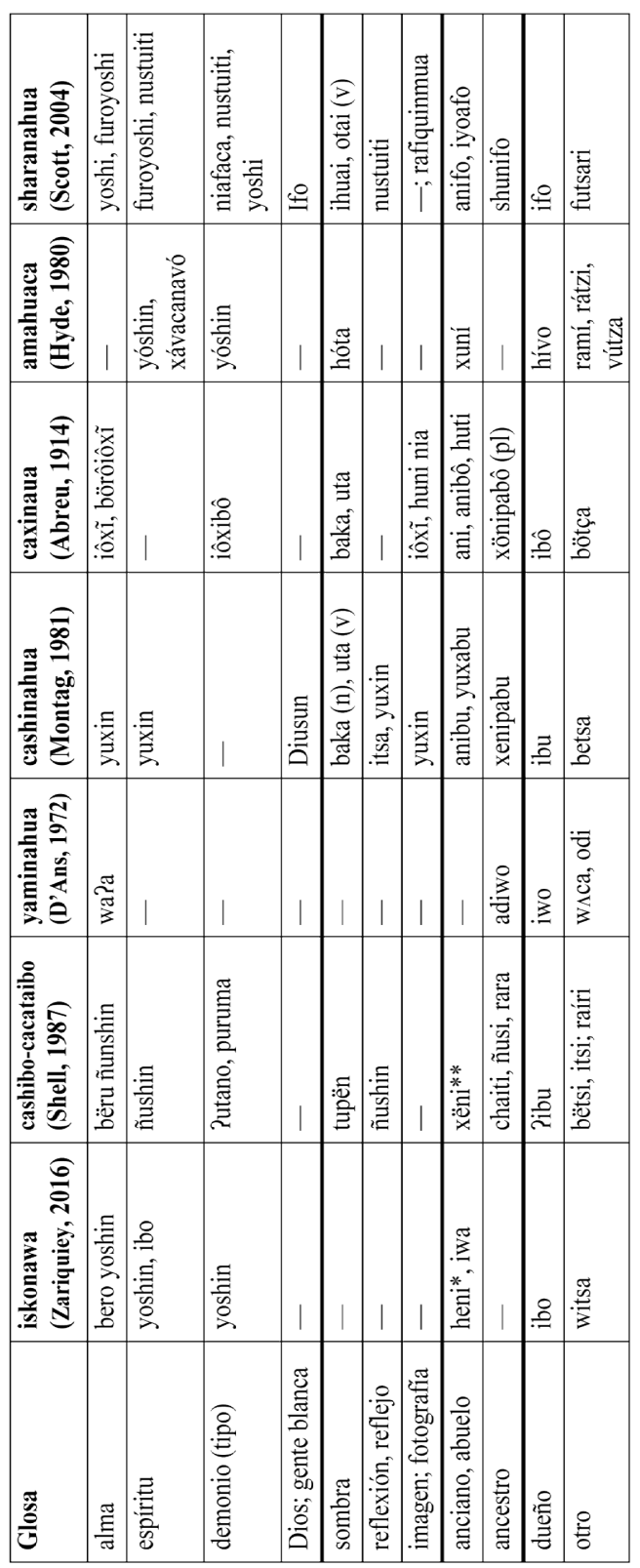

* En el diccionario de Zariquiey (2016), heni 'viejo' refiere principalmente a objetos.

** En el diccionario de Shell (1987), xëni 'viejo' refiere principalmente a objetos. 


\section{CAJAVILCA - CUESTIONES ETIMOLÓGICAS DEL ALMA ORIGINARIA}

\subsection{El término original de sombra para nombrar al alma}

Yoshin es traducido también como 'sombra' en capanahua (LOO); ñushin, 'reflejo' en cashibo-cacataibo (SHE); yuxin, 'reflejo', 'imagen' en cashinahua (MON); iôxĩ ' 'imagen' en cashinahua (ABR). Tal repertorio hace pensar que yoshi podría haberse derivado de sombra, sin embargo, no se trataría más que de una generalización. Así, por ejemplo, el almasombra de los cashinahua reportada por Yano (2009), yuda baka yuxin, puede simplemente expresarse yuxin, aunque puede tratarse también de una simplificación del lexicógrafo al momento de anotarlo en su cuaderno. Por otro lado, no es extraño que posteriormente, este término abstracto haga referencia a la sombra concreta (silueta formada por el bloqueo de la luz) en paralelo a un término ya existente para el concepto de sombra. Véase en el Cuadro 1, el término capanahua (LOO) yoshin 'espíritu' ha pasado a significar 'sombra' formando una relación de sinonimia con hota 'sombra'. ¿Si yoshi no se deriva de sombra, reflejo o imagen entonces de dónde? Primero debemos descartar esta posibilidad.

Según el Cuadro 1, son dos las lenguas que usan la palabra caya para señalar al 'alma': ${ }^{14}$ el shipibo (LOR) y el capanahua (LOO); y una lengua que reporta mayan: el matses (FLE). Al revisar el diccionario, observamos que cáya en el shipibo de LOR tiene como primera y segunda acepción ${ }^{15}$ a la 'sombra' y el 'reflejo' respectivamente, y solo como tercera acepción al 'alma'; el contraste lo establece el matses (FLE), en el cual 'sombra' aparece como tercera acepción y 'espíritu', 'demonio' y 'alma' aparecen como primeras acepciones. Recordemos que 'espíritu', 'demonio' son palabras que denotan conceptos occidentales y no son apropiados para tomarlos como referencias etimológicas. Su traslación hacia aquellas palabras castellanas es debido a meras cuestiones interculturales. Por consiguiente, para develar los orígenes etimológicos de caya y mayan debemos indagar en el campo semántico de la sombra. Como es usual el concepto de sombra está vinculado a la luz o a sus agentes causales, como el sol, generador natural de luz, o la fogata durante la noche; asimismo está vinculado al concepto de oscuridad y sus derivados (abrigo, techo, corteza, cubrir). Por ejemplo, en cunibo (ANO) encontramos un término que sorprendentemente parece sintetizar el mayan del matsés y el cáya del shipibo en la idea de 'mediodía': mama queya, barimanqueya yaccata. Igualmente, en el sipibo de STE: barimanqueya racáta 'mediodía'.

El caya del shipibo (LOR) y del capanahua (LOO), sería una raíz cuyo significado habría estado vinculado al tiempo y posición del sol; en el amahuaca de HYD encontramos esta raíz en el término cáyaahi 'temprano'. Hallamos evidencia de un morfema -ya(t) en los diccionarios del capanahua y shipibo con el significado de temprano y mañana. Por otro lado, el término queyá 'alto' (LOR) es empleado para formar el concepto de cenit ${ }^{16}$ o mediodía, por ejemplo, en la oración ea bári queyáque 'me [levanté] con el sol del

${ }^{14}$ En el vocabulario yaminahua de d'Ans (1972), se reporta wa?a con el significado de 'alma', sin embargo, no lo tomaré en cuenta para el análisis debido a que no tiene cognados dentro de la familia linguística. Por otro lado, es realmente desconcertante que esta palabra, wa? a, se parezca bastante a wa?an 'jefe', 'dueño' de las lenguas cahuapanas.

${ }^{15}$ Por lo general, según el correcto desarrollo de un diccionario, el orden de las acepciones debe reflejar la frecuencia de uso.

${ }^{16}$ La palabra cenit también tiene connotaciones de 'alto' y 'cabeza'. Viene del árabe semt ar-ra's 'el paraje de la cabeza' (cf. Corominas 1987: 144). 
mediodía' ${ }^{17}$. Por lo tanto, bári queyáque indica literalmente 'el sol en lo alto'. Hay muchas maneras de pasar de alto a sombra, tanto conceptual como estructuralmente, pero no vamos a entrar en detalle, solo diremos que / keya/ presenta alternancias sincrónicas que incluye /kaya/. Señalaré nuevamente las evidencias en la siguiente lista, incluyendo datos del cashinahua (MON).

(1)

cáyaahí
-yaht, -yat
queyá
-ya
queyá
queyáti
keya

keyatapa

badi kayadan ${ }^{18}$

ma badi keyaki

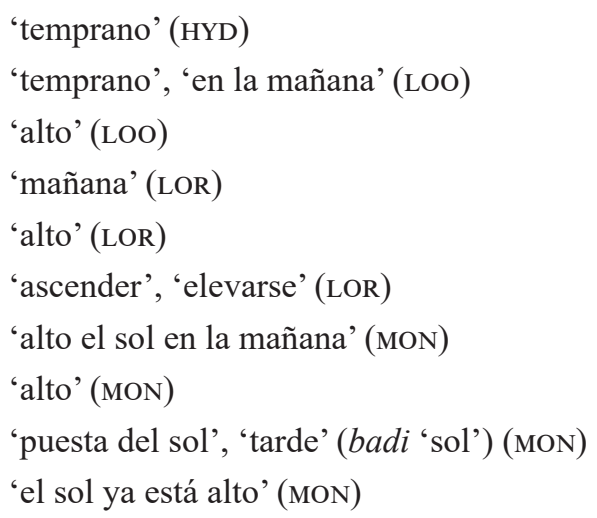

En el Apéndice F del diccionario de Loo, se señalan términos relacionados con el tiempo. ${ }^{19}$ Entre ellos, encontramos términos que contienen una notoria raíz *ya-.

$$
\begin{aligned}
& \text { yamé } \\
& \text { yamé naex } \\
& \text { yamé nete } \\
& \text { yaméquiri } \\
& \text { yameti } \\
& \text { yantan } \\
& \text { yantani }
\end{aligned}
$$

Finalmente, el mayan del matsés ('sombra', 'alma'), al igual que caya, tiene vínculos significativos con el tiempo y posición del sol. Por ejemplo, en el diccionario capanahua (LOO), el adverbio mananho 'en altura' está compuesto de la misma raíz que compone el nombre manan 'colina' y el adverbio barin manan tsahcahiya ${ }^{20}$ 'al mediodía' (lit. 'cuando el sol da con el cenit', de barín 'sol' y tsahca- 'chocar'). En la siguiente lista observamos una hipotética base morfemática $* m a(n)$ que compone términos con significados relacionados que señalan un objeto de gran altura o lugar situado en lo alto.

${ }^{17}$ La frase se localiza en el lema báchi en Loriot et al. (1993: 99).

${ }^{18}$ No encabeza lema (cf. Montag 1981: 226, 416).

${ }^{19}$ Aparecen palabras compuestas con un morfema -ma- (Loos \& Loos: 508), pero no podemos suponer aventuradamente que se trata del mismo morfema de mayan del matsés.

${ }^{20}$ La frase adverbial barin manan tsahcahiya 'al mediodía' se encuentra como lema en el diccionario (Loos \& Loos 1998: 69). 


$\begin{array}{ll}\text { mannan } & \text { 'cima', 'cumbre' (FLE) } \\ \text { mas- } & \text { 'colina' (LOO) } \\ \text { mash- } & \text { 'sobre la cabeza', 'sobre la parte superior' (LOO) } \\ \text { mayasameti } & \text { 'encima de', 'por la cabeza' (LOO) } \\ \text { manan } & \text { 'posar encima de', 'estar encima de' (LOO) } \\ \text { maníti } & \text { 'arriba' (SHE) } \\ \text { mánan } & \text { 'estar el sol en el cenit' (SHE) } \\ \text { mánan } & \text { 'cerro', 'sitio alto' (MON) } \\ \text { mana } & \text { 'cerro', 'sitio alto' (HYD) } \\ \text { maná mascati } & \text { 'cerro', 'monte' (ALE) } \\ & \text { 'cumbre de cerro' (DES) }\end{array}$

\subsection{Las traducciones y posible origen semántico del término yoshi}

Yoshi aparece con diversas traducciones en los diccionarios consultados (véase Cuadro 1): 'espíritu', 'alma', 'sombra', 'reflejo', 'imagen', '(tipo de) demonio', 'anciano', 'antepasado', 'Dios'. No obstante, se debe incluir en esta lista a aquel término vinculado con el tamaño o la peculiaridad de ciertos animales representativos de su especie. Se ha verificado que cierta raíz *yosi $(n)^{21}$ conforma, por ejemplo, los siguientes nombres comunes: yóshinporó 'especie de gusano grande' (HYD), iôxĩ-xötaya 'perezoso grande' (ABR), šhónoyoshin 'madre de la lupuna' (LOR). Estas especies forman una categoría aparte en la cosmovisión de los pano (volveré sobre este asunto más adelante).

Si clasificamos todas estas traducciones, según una organización semántica, obtendremos tres grupos más o menos diferenciados: I, II y III. La clasificación es importante para dilucidar y postular un posible significado primitivo de yoshi. Por lo tanto, el significado original tendría tres posibilidades (no concluyentes) como se observa en el Cuadro 2:

Cuadro 2: Significados de yoshi según el Cuadro 1

\begin{tabular}{|c|l|l|}
\hline Grupo semántico & \multicolumn{1}{|c|}{ Traducciones } & $\begin{array}{l}\text { Cantidad de diccionarios en los } \\
\text { que aparece el término }\end{array}$ \\
\hline I & alma, espíritu, demonio, Dios & $3,7,10,1$ \\
\hline II & sombra, reflejo, imagen & $1,2,2$ \\
\hline III & anciano, abuelo, ancestro & $8,4,0$ \\
\hline
\end{tabular}

$21 * \operatorname{Yosi}(n)$ es la protoforma sugerida por Oliveira (2014) y que en su defecto podría alternar con *yoši(n) debido a la alofonía perenne entre el sonido fricativo alveolar y el postalveolar ante la vocal alta anterior [i] (ibíd.: 254).

${ }^{22}$ Esta columna refiere acerca de cuántos diccionarios reportan yoshi con una de las traducciones específicas. Por ejemplo, yoshi con la traducción de 'imagen' aparece solo en dos diccionarios del Cuadro 1; con la traducción de 'espíritu' aparece en siete diccionarios del Cuadro 1. 
El grupo I, a todas luces, no garantiza ninguna posibilidad de originalidad. En efecto, ‘alma', 'espíritu', 'demonio'y ‘Dios' son conceptos foráneos y portan significados sintetizados por la ideología cristiana. Según el contexto y el rol que cumple yoshi para la persona, pueden darse los siguientes casos de interpretación: cuando yoshi actúa como padre protector puede ser traducido como el 'Dios' cristiano; cuando actúa como entidad vengativa, es el 'demonio'; cuando actúa como un ser neutral que vaga por el bosque a sus anchas, es el 'espíritu'; a su vez, el propio principio vital de la persona es capaz de convertirse en yoshi-espíritu cuando sobrevienen ciertas condiciones. Para el nativo pano, todos estos son yoshi con diferentes interpretaciones, aunque los occidentales sientan que es prescindible otorgarles diferentes significados. Las asignaciones de estos conceptos se han realizado en épocas recientes, que podría haber sido en el tiempo de las primeras misiones evangélicas en la Amazonía.

Respecto al grupo II, yoshi es empleado con el sentido de 'sombra', 'imagen', 'reflejo' solo en tres lenguas: capanahua, cashinahua y cashibo-cacataibo (véase Cuadro 1). La baja frecuencia es debido a que los conceptos de sombra o imagen tienen su terminología patrimonial (véase $\S 2.3$ ). La asignación conceptual de sombra a yoshi es parte de un mecanismo de reinterpretación semántica. Por lo tanto, los conceptos del grupo II tampoco serían los originales de yoshi; es decir, no he encontrado rastros etimológicos dentro de la familia lingüística que me hagan suponer que yoshi haya tenido el significado primitivo de sombra, imagen o similar.

Los términos que refieren a los conceptos del grupo III (anciano, abuelo, ancestro) son aquellos que tienen forma parecida a yoshi, aunque también hay otros términos con el mismo significado que no han sido contabilizados en el Cuadro 2 y que no tienen relación léxica con yoshi, como es el caso de chichi, xano, tsabe 'abuela' y xohta, chahi ‘abuelo' (LOO). Esto sugiere que yoshi con el significado de «anciano» no es más que una adaptación posterior. Además, los términos de familia son menos básicos como para derivar la noción de alma o espíritu.

No obstante, hay algunas formas compuestas que parece sugerir que yoshi tendría un vínculo etimológico con los conceptos de anciano y grande. Por ejemplo, el nombre del cóndor hishmin chichi (hishmin 'buitre', chichi 'abuela', LOO) invita a pensar que en el caso de s̈hónoyoshin 'madre de la lupuna' (s̈hóno 'lupuna', LOR) hay que seguir la misma estructura semántica. Asimismo, uno observa que anibu 'anciano' (MON) está formado por $a n i$ 'grande' y $-b u^{23}$ que es un pluralizador y también un clasificador para 'gente' (lit. 'gente grande'), al compararlo con yosibo 'anciano' (LOO) nos vuelve a sugerir la misma analogía, en este caso que yosi- sería equivalente a «grande». En el siguiente capítulo vamos a demostrar que la relación léxica entre yoshi y los términos con significados del grupo III no es una relación etimológica.

\subsection{Yoshi como elemento de nombres compuestos}

Los yoshi que componen al ser humano son nombres compuestos que tienen la estructura $\mathrm{N}_{\mathrm{Com}}+\mathrm{N}_{\mathrm{Nuc}}$. Estos son algunos que menciona Yano para el cashinahua: bedu

${ }^{23}$ La protoforma sugerida es *- $\beta$ o (cf. Oliveira 2014). Es un sufijo pluralizador, aumentativo, clasificador de 'gente', 'ser humano'.

LIAMES, Campinas, SP, v. 19, 1-25, e019002, 2019 
yuxin 'yuxin del ojo', yuda baka yuxin 'yuxin de la sombra corporal', isun yuxin 'yuxin de la urina', pui yuxin 'yuxin de las heces', nama yuxin 'yuxin de los sueños' (cf. Yano 2009: 71). La posición nuclear de yoshi en el nombre compuesto va a resaltar a la entidad espiritual sobre el elemento del cual se origina, es como una sombra desencarnada; así, por ejemplo, bedu yuxin 'yuxin del ojo' es el espíritu asentado en el ojo; s̈hónoyoshin (LOR) es el espíritu que habita en la lupuna, no la lupuna misma. Según Lagrou, los cashinahua llaman a la lechuza pupu yuxin, en contraste MON registra yuxin pupu para la misma lengua. Aunque en la práctica pueden confundirse, formalmente ambos tienen diferentes significados debido al elemento que funciona como núcleo. La siguiente cita lo aclara: «Y escuchar el grito desgarrador de la lechuza, pupu yuxin, es un signo de la muerte inminente de un pariente cercano. Se dice que la lechuza es definitivamente más yuxin que cuerpo» (Lagrou 1998: 46). Por lo tanto, yuxin pupu no se refiere a la entidad invisible, en contraste a pupu yuxin, sino a una especie animal que posee yoshi (véase al respecto más adelante). Ahora se entiende por qué s̈hónoyoshin es traducido como 'madre de la lupuna' (LOR), haciendo alusión al espíritu invisible que vela por la lupuna. Algunos ejemplos de yoshi en posición nuclear:

$$
\begin{aligned}
& \text { s̈hónoyoshin } \\
& \text { canáyoshin } \\
& \text { jenényoshin } \\
& \text { panányoshin } \\
& \text { béroyoshin }
\end{aligned}
$$

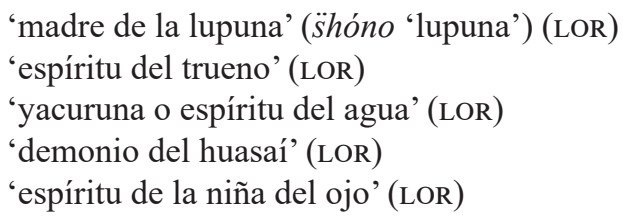

Ahora bien, el concepto madre de $x$ tiene la misma interpretación de 'padre', 'amo' o ‘dueño' de x como se comprueba en los reportes etnográficos. Es común encontrar en el pensamiento amazónico la idea de que las especies tienen «dueño» ${ }^{24}$ (cf. Eliade 1999: 29; Descola 2005: 130, 135; Surrallés 2009: 170, 209; Goulard 2009: 285-6, 307). El dueño también se interpreta como el conductor de la especie, un padre protector que no tiene problemas en compartir, pero que también puede ser vengativo cuando abusan de su generosidad. En el Cuadro 1, podemos observar palabras como ibo, hihbo, icbo, Pibu con la traducción de 'dueño', pero también puede aparecer con la traducción de 'padre', 'madre' (ABR) e incluso 'Dios' (LOR). Veáse la siguiente lista en donde los nombres compuestos por *?i? $\beta o$ 'dueño' y por *iwa 'madre' básicamente tendrían el mismo significado de madre de $X$, aunque los diccionarios reportan otras traducciones:
bukun ibu
bokon ibo
bahuán ehua
ronón ehua
hiamaheua
hina eua
'esp. de hormiga' (bukun 'cetico', ibu 'dueño') (MON)
'esp. de hormiga' (dueña del cetico) (ZAR)
'esp. de loro grande' (ehua 'madre') (LOR)
'boa' (ronón 'serpiente') (LOR)
'laguna grande' (hia 'laguna') (STE)
'charapa macho' (hina 'animal doméstico') (STE)

${ }^{24}$ Gramaticalmente, la composición nominal $\mathrm{N}+\mathrm{N}$ que indica una relación de origen o identidad $(x$ procede de $y$ o $x$ es $y$ ) no requiere marcador genitivo; mientras que la composición $\mathrm{N}+\mathrm{N}$ que indica posesión ( $x$ que pertenece a $y$ ) sí requiere de marcador genitivo obligatorio. 
suya eua

yauama eua

inon ewa

koman ewa

?oba $\Lambda$ wa

hishmin chichi 'cuy de la sierra' (suya 'ratón') (STE)

'cerdo', 'puerco'25 (yaua 'jabalí') (STE)

'esp. felino grande' (ewa 'madre') (ZAR)

'esp. perdiz grande' (koman 'perdiz') (ZAR)

'perdiz grande' (DAN)

'abuelo de cóndor' (hishmin 'cóndor', 'buitre') (LOO)

Bukun ibu, de la lista anterior, tal como es reportada en MoN, indica el nombre de un tipo de hormiga, sin embargo, literalmente expresaría 'dueño del cetico' ${ }^{26}$ De igual forma bahuán ehua lit. 'madre del loro'. Comparando las listas 4 y 5 , ¿habría sido madre/dueño el significado original de yoshi? El problema con esta propuesta es que yoshi no se conecta léxicamente con los conceptos de madre, padre o dueño. La lectura de s̈hónoyoshin como 'madre de la lupuna' es una interpretación castellana, aunque acertada no quiere decir que -yoshin signifique 'madre'. Asimismo, atribuir los conceptos de anciano y ancestro como los significados originales de yoshi nos llevaría a una cuestión circular; lo más probable es que todos aquellos términos del Cuadro 1 parecidos a yoshi (p. ej. yósi, yúse, yusi) y que significan 'anciano', 'abuelo' y 'ancestro' serían formas derivadas.

En otro tipo de nombre compuesto $\left(\mathrm{N}_{\mathrm{Com}}+\mathrm{N}_{\mathrm{Nu}}\right)$, yoshi va a funcionar como complemento nominal, mientras que el nombre simple de la especie funciona como núcleo. Véase los siguientes nombres de animales:

$\begin{array}{ll}\text { yóshinporó } & \text { 'esp. de gusano grande' (HYD) } \\ \text { iôxĩ-xötaya } & \text { 'perezoso grande' (ABR) } \\ \text { yuxin pisa } & \text { 'esp. de pinsha o tucán' (MON) } \\ \text { yuxin pupu } & \text { 'esp. de lechuza' (MON) } \\ \text { yoshin tsóhihca } & \text { 'grillo negro' (LOO) } \\ \text { yoshíncapa } & \text { 'esp. de ardilla grande y roja' (cápa 'ardilla') (LOR) } \\ \text { yoshín ípo } & \text { 'carachama pequeña con cuernos' (LOR) } \\ \text { joshímaque } & \text { 'esp. de paña grande' (LOR) } \\ \text { yóshiman boéšheti } & \text { 'esp. de pez de tamaño pequeño' (LOR) } \\ \text { yóshiman pás̈hoquiriti } & \text { 'esp. de pez de tamaño largo' (LOR) }\end{array}$

Basado en estas simples traducciones, uno podría asumir que yoshi tiene el significado de 'grande', sin embargo, no es tan sencillo como parece. Cuando yoshi aparece como complemento nominal, el nombre compuesto va a denotar a una especie animal cuyo atributo es ser yoshi (predicado de la forma $x$ es $y$ ). Lagrou nos da una idea de qué son estos animales-yoshi:

El orden del tiempo que sigue la alternancia rítmica de día y noche, luz y oscuridad, actividad corporal y actividad yuxin es la raíz del dualismo cosmogónico cashinahua y aquellos animales que traspasan estos límites, gritando, cantando o moviéndose durante la noche en lugar de dormir, son

${ }^{25}$ Observe como el animal traído por los españoles es considerado, por los shipibos, extraño, peculiar. Del mismo modo, el cuy de la sierra. El morfema-raíz eua refiere en primera instancia a algo grande.

${ }^{26} \mathrm{El}$ hecho de que bukun ibu haya sido lexicalizado para nombrar a un tipo de hormiga no viene al caso. Lo que se considera, más bien, es el análisis estructural de las raíces y sus significados independientes. 
Son entonces animales visibles (corporalidad), pero que pertenecen a ambos mundos, su formación léxica requiere que el nombre de la especie esté en posición nuclear $\left(\mathrm{N}_{\text {Com }}+\mathrm{N}_{\mathrm{Nuc}}\right)$. Por otro lado, la posición prenuclear de yoshi también es la del adjetivo en la gramática de las lenguas pano, por lo tanto, yoshi también está indicando una propiedad que caracteriza a la especie. Esta construcción es similar a las formadas con el adjetivo «grande»en posición prenuclear:

$$
\begin{aligned}
& \text { awa xukö } \\
& \text { nawa kanó } \\
& \text { nawa kashi } \\
& \text { awá popokiri } \\
& \text { awa hoke } \\
& \text { ánicape } \\
& \text { ániatapa } \\
& \text { cayánari }
\end{aligned}
$$
'esp. de tucán grande' (xôkö ‘tucán', öwa 'grande’) (ABR) 'esp. de ave grande' (kana 'guacamayo') (ZAR) 'esp. de murciélago grande' (kashi 'murciélago') (ZAR) 'esp. de mariposa grande' (popókiri 'mariposa') (ZAR) 'esp. de tucán grande' (hoke 'tucán') (ZAR) 'lagarto grande' (áni 'grande', 'crecer') (LOR) 'esp. de gallina grande' (LOR) 'esp. de tibe (ave) grande' (LOR)

El elemento que funciona como complemento nominal, en los nombres compuestos de la lista 7, refuerza la sugerencia de que el término yoshi de la lista 6 tendría el significado de 'grande', ¿habría sido este concepto el significado original de yoshi? Lo único que daría cuenta de esta hipótesis es un verbo que aparece en solo tres diccionarios: yusi- 'crecer' (MON), yosi 'crecer' (SCO), yoši i- 'crecer' (DAN); y un adjetivo: yausi 'grande' (CAS). ${ }^{27} \mathrm{Sin}$ embargo, no es suficiente para confirmar un camino etimológico. La gran cantidad de cognados para *(n)awa ${ }^{28}$ y para $* 2 a n i^{29}$ deja en segundo plano a yoshi; por lo tanto, su significado de 'grande' es solo connotativo.

Debemos volver a la información etnográfica y evaluar la descripción anterior que hace Lagrou sobre el esquema dualista de los cashinahua y también tomando en cuenta aquel aspecto desconcertante de yoshi relatado por Bertrand-Rousseau (1986): es lo otro, lo extraño. La alternancia entre el día y la noche, la actividad corporal versus la actividad yoshi que es la actividad de los animales-yoshi, bastante temidos por las personas por lo que evitan sus encuentros. La noche es, pues, un destacado aspecto metafísico de los animales-yoshi. Ahora bien, si tomamos el concepto de noche como una referencia etimológica vamos a encontrar que no hay una conexión léxica con yoshi ${ }^{30}$ Sin embargo, existe un sufijo verbal temporal -shi que designa a la acción verbal realizada durante la

${ }^{27}$ En apéndice de Castelnau (1851: 292).

${ }^{28}$ Algunos cognados: öwa, owã 'grande', 'crecer' (ABR), öwana 'crecer', 'hacerse viejo' (ABR), öwapa 'muy grande' (ABR), öwa 'madre', 'anciana' (ABR), nawa 'gente' (ABR), eva- 'ser grande' (MON), evapa 'grande' (MON), nava 'persona extranjera' (MON), ewa 'madre' (ZAR), nawa 'mestizo', 'extranjero' (ZAR), dawa 'gente' (DAN).

${ }^{29}$ Algunos cognados: xeni 'grande' (MON), kani- 'desarrollar', 'crecer' (MON), kani 'madurar' (ABR), tani 'crecer' (SCO), cani 'crecer' (FLE), áni 'grande', 'crecer' (LOR), caniti 'crecer' (SHE), ani 'cosa grande' (STE).

${ }^{30}$ Algunos términos que denotan 'noche', ninguno tiene conexión con yoshi: inchësh 'oscuridad', 'noche' (FLE), yamé 'noche', 'oscuridad' (LOO), yamé 'noche' (LOR), yamué 'noche' (NAV), yamue 'noche' (STE), bakish 'noche', 'oscuro' (ZAR), imé 'noche' (SHE), yame- 'oscurecer', mexumedan 'oscuridad' (MON), iamö 'noche' (ABR), yámuи 'noche' (HYD), уати 'noche' (SCO). 
noche, ¿sería este morfema parte también del término yoshi? Si es así, la palabra estaría formada por una raíz verbal; no obstante, esta raíz tendría que puntualizar los datos de la etnografía: existen unos seres que realizan sus actividades de noche, pero qué tipo de actividades, pues las mismas que realizan los hombres durante el día, cazan, pescan, conversan, o como dice la cita anterior de Lagrou: «gritando, cantando o moviéndose durante la noche en lugar de dormir». Existe, pues, un verbo que significa decir (*yo?i-), pero es más usado con el sentido de relatar, contar, incluso también cantar; una actividad milenaria de las sociedades que consiste en transmitir sus conocimientos y sus mitos. Véase la siguiente tabla.

Cuadro 3: La raíz verbal DECIR y el sufijo adverbial durativo

\begin{tabular}{|c|c|c|}
\hline Diccionario & «DECIR» (raíz verbal) & «NOCHE» (sufijo adverbial) \\
\hline matsés (Fleck, 2012) & chui 'relatar', 'aconsejar', 'consultar' & inchësh 'oscuridad', 'noche' \\
\hline capanahua (Loos, 1998) & yohi- 'hablar', 'decir', 'contar' & -shina 'toda la noche' \\
\hline shipibo (Loriot, 1993) & yói- 'hablar', 'decir', 'explicar' & -shin 'toda la noche' \\
\hline pano (Navarro, 1903) & yui 'amonestar', 'avisar', 'narrar' & chishi 'anoche' \\
\hline sipibo (Steinen, 1904) & yui- 'avisar', 'decir' & - \\
\hline iskonawa (Zariquiey, 2016) & yoi 'contar' & -ne 'durante la noche'31 \\
\hline cashibo-cacataibo (Shell, 1987) & ñui- 'decir', 'explicar', 'relatar' & -nët' durante la noche'32 \\
\hline cashinahua (Montag, 1981) & $\begin{array}{l}\text { yui 'decir', 'contar'; } \\
\text { yuan 'cantar' }\end{array}$ & -xin 'durante la noche' \\
\hline caxinaua (Abreu, 1914) & $\begin{array}{l}\text { iôi 'decir'; } \\
\text { miyôi 'contar historia' }\end{array}$ & $\begin{array}{l}\text {-xi 'actividad realizada toda la } \\
\text { noche' }\end{array}$ \\
\hline amahuaca (Hyde, 1980) & yóhi- 'decir', 'hablar' & -shin 'ayer'33 \\
\hline sharanahua (Scott, 2004) & yoi 'hablar', 'decir', 'anunciar' & -shi 'toda la noche o de noche' \\
\hline
\end{tabular}

Un hecho interesante es que las formas fonémicas que se manifiestan en las palabras del Cuadro 3 son las mismas formas manifestadas para yoshi en el Cuadro 1; por ejemplo, en cashibo-cacataibo (SHE), tenemos ñushin 'espíritu' con la nasal palatal, /nušin/, mientras que, en el Cuadro 3, tenemos /nui/ 'decir' también con nasal palatal.

Entonces, yoshi estaría expresando una actividad importante en las culturas amazónicas y que ha pasado a definir a los seres que la realizan. Los animales-yoshi también se reúnen - alrededor de su abuelo - y cuentan las historias de sus ancestros o tal vez están planeando como cazar a los yoshi de los hombres. Qué son los gemidos y chirridos que se escuchan por las noches, pues no es más que su lengua, que a los oídos de los hombres solo son gruñidos. Finalmente, la relación léxica entre yoshi y los términos con significados del grupo III (Cuadro 2) es de divergencia, cuyo origen en común sería

${ }^{31}$ El sufijo no es similar al resto, pero se cumple con mostrarlo (cf. Zariquiey 2015).

${ }^{32}$ El sufijo no es similar al resto, pero se cumple con mostrarlo (cf. Zariquiey 2011).

${ }^{33}$ El sufijo no se reporta en el diccionario de Hyde. Consúltese en Sparing-Chávez (2012). 
este verbo decir. En el matsés encontramos un rastro de esta evidencia: la palabra chuiquid 'jefe', 'curaca' (FLE) es la forma derivada de chui 'relatar' y el sufijo agente nominalizador -quid, literalmente 'el que cuenta historias', una función atribuida a los ancianos de la aldea, los abuelos y patriarcas por antonomasia.

\section{Conclusiones}

Con excepción del grupo I (Cuadro 2), que son adaptaciones manipuladas por el contacto cultural, los significados de los grupos II y III son extensiones semánticas surgidas en paralelo en los albores de la creación del concepto de los animales-yoshi. La razón de que exista yoshin como 'sombra' (LOO) y yósi como 'anciano' (LOR), se debe a que ambos son productos de una extensión semántica de la palabra original que designaba a los animales-yoshi.

Ahora bien, los orígenes etimológicos de alma no deberían involucrar un número ilimitado de palabras y conceptos. Piense, por ejemplo, en el concepto de hombre, ¿hay alguna razón para asumir que el origen de la palabra tendría infinitas posibilidades?, pues de hecho no. Las fuentes conforman un número limitado de palabras que, si bien no debe tomarse como una generalización universal, establece una importante tendencia para adecuar una metodología. Respecto al alma, la dimensión etimológica se circunscribe a dos clases de nociones básicas, siguiendo la descripción de Hultkrantz: el alma corporal que involucra las palabras que denotan nacimiento, calor, aliento, aire, los nombres de órganos y fluidos; y el alma libre que involucra las palabras que denotan sombra, imagen (de los sueños), reflejo, doble, otro, semejante, imitación, parecido o parecerse. Por otro lado, las palabras no solo pueden derivarse directamente manteniendo la base léxica estable, sino también empleando una construcción gramatical, como es el caso de yoshi, derivada de raíz y morfema. Asimismo, los dos casos de terminología básica constituyen los ejemplos comunes que han sido verificados hasta ahora por la etnografía y la literatura (véase los ejemplos en $\S 1$ ), no obstante, esta lista puede extenderse para ambos casos.

El análisis comparativo no solo ayuda a establecer un espacio etimológico, sino que también pone en evidencia lo que se describe en la etnografía. Al final, la misma palabra debe reflejar, en su significado original, los aspectos ontológicos del alma. Lagrou sintetiza muy bien estos aspectos del alma-espíritu de los cashinahua bajo dos epígrafes y que puede generalizarse a los demás pueblos pano: es la fuerza vital y el ser poderoso o doble (cf. Lagrou 1998: 37). Si yoshi hubiese sido descrito como el principio invisible que hace posible el latido del corazón y que está fijado al cuerpo mientras se está vivo, entonces el examen etimológico debería partir de esta información. Ahora sabemos cuán relevante es partir de la información etnográfica; el análisis lingüístico por sí solo se perdería en una autopista sin salidas. En principio, yoshi es el otro, el extraño, de este modo, las sombras de la oscuridad (los animales-yoshi) se convirtieron en el principio de sostenimiento, se convirtieron en un concepto que necesitaban para explicar la fuerza y el principio vital del cuerpo. Lo extraño se convirtió en algo familiar. Yoshi es, por lo tanto, una fusión entre el alma corporal, el alma libre y el espíritu del bosque, mientras que caya, el alma-sombra, alude al alma libre solamente. Siendo, entonces, consecuente con lo que habíamos afirmado en la introducción, el alma libre (que en occidente se convirtió en un 
ente despreciado) ha jugado un rol protagónico en la cosmovisión de los pano, pues no solo ha creado una palabra, sino también a moldeado la realidad objetiva produciendo una red viviente con capacidad para comunicarse.

\section{Referencias}

Bayet, Jean (1984). La religión romana. Historia política y psicológica. Madrid: Ediciones Cristiandad.

Bertrand-Rousseau, Pierrette (1986). La concepción del hombre entre los shipibos. Anthropologica 4(4): 92-114.

Blázquez, José María; Martínez-Pinna, Jorge; Montero, Santiago (2011). Historia de las religiones antiguas: Oriente, Grecia y Roma. Tercera edición. Madrid: Cátedra.

Bremmer, Jan N. (2002). El concepto del alma en la antigua Grecia. Madrid: Siruela.

Daryaee, Touraj (2012). The Oxford Handbook of Iranian History. Nueva York: Oxford University Press.

Descola, Philippe (2005). Las lanzas del crepúsculo. Relatos jíbaros. Alta Amazonia. Buenos Aires: Fondo de Cultura Económica.

Dixon, Robert M. W.; Aikhenvald, Alexandra Y. (1999). The Amazonian languages. Nueva York: Cambridge University Press.

Eliade, Mircea (1999). Historia de las creencias y las ideas religiosas. De la Edad de Piedra a los misterios de Eleusis, vol. 1. Barcelona: Paidós.

Friedmann, Claude T. H.; Faguet, Robert A. (1982). Extraordinary disorders of human behavior. Nueva York: Plenum Press.

Galimberti, Umberto (2002). Diccionario de psicología. Ciudad de México: Siglo xxI.

Goulard, Jean-Pierre (2009). Entre mortales e inmortales. El Ser según los ticuna de la Amazonía. Lima: CAAAPIFEA.

Holman, Eric W.; Wichmann, Søren; Brown, Cecil H.; Velupillai, Viveka; Müller, André; Bakker, Dik (2008). Explorations in automated language classification. Folia Linguistica 42(2): 331-354.

Hope, Valerie M. (2007). Death in ancient Rome: A sourcebook. Nueva York: Routledge.

Hultkrantz, Åke (1979). The religions of the American indians. Berkeley: University of California Press.

Lagrou, Elsje Maria (1998). Cashinahua cosmovision: A perspectival approach to identity and alterity (Ph.D. dissertation). Fife: University of St. Andrews.

López Austin, Alfredo (2004 [1989]). Cuerpo humano e ideología: Las concepciones de los antiguos nahuas. Tercera edición. México: Instituto de Investigaciones Antropológicas - UNAM.

Neumann, Erich (1989 [1954]). The origins and history of consciousness. Londres: Maresfield Library. 


\section{CAJAVILCA - CUESTIONES ETIMOLÓGICAS DEL ALMA ORIGINARIA}

Oliveira, Sanderson Castro Soares de (2014). Contribuições para a reconstrução do Protopáno (Tese de doutorado em linguística). Brasília: Universidade de Brasília.

Onians, Richard Broxton (2000 [1988]). The origins of european thought: About the body, the mind, the soul, the world, time and fate. Cambridge: Cambridge University Press.

Ribeiro, Camila Silva (2014). Mergulho no ser. Corpo e memória em cerimônias indígenas com Huni (Tese de mestre em psicologia). Ribeirão Preto: Universidade de São Paulo.

Rohde, Erwin (1948). Psique: La idea del alma y la inmortalidad entre los griegos. México: Fondo de Cultura Económica.

Sparing-Chávez, Margarethe (2012). Aspects of Amahuaca grammar: An endangered language of the Amazon Basin. Lima: SIL.

https://www.sil.org/system/files/reapdata/34/91/01/34910139906464610997281841007414500104/eBook 51 Sparing_Ch\%C3\%A1vez_Amahuaca_Grammar.pdf

Surrallés, Alexandre (2009). En el corazón del sentido. Percepción, afectividad y acción en los candoshi (Alta Amazonía). Lima: IFEA/IWGIA.

Townsley, Graham (1993). Song Paths. The ways and means of Yaminahua shamanic knowledge. L'Homme 33(126-128): 449-468.

Vernant, Jean-Pierre (2006). Myth and thought among the Greeks. Nueva York: Zone Books.

Vilaça, Aparecida (1992). Comendo como gente: Formas do canibalismo Wari'. Rio de Janeiro: Universidade Federal do Rio de Janeiro.

Viveiros de Castro, Eduardo (1986). Araweté, os deuses canibais. Rio de Janeiro: Jorge Zahar.

Weiss, Gerald (1972). Campa cosmology. Ethnology 11(2): 157-172.

Weiss, Gerald (1975). Campa cosmology: The world of a forest tribe in South America. Nueva York: The American Museum of Natural History.

Yano, Ana Martha Tie (2009). A fisiologia do pensar: Corpo e saber entre os Caxinauá (Tese de mestre em antropologia social). São Paulo: Universidade de São Paulo, Programa de Pós-Graduação.

Zariquiey Biondi, Roberto (2011). A grammar of Kashibo-Kakataibo (Tesis de doctorado). Bundoora, Victoria: La Trobe University, Faculty of Humanities and Social Sciences.

Zariquiey Biondi, Roberto (2015). Bosquejo gramatical de la lengua iskonawa. Lima: Latinoamericana Editores.

Zusne, Leonard; Jones, Warren H. (2014 [1989]). Anomalistic psychology: A study of magical thinking. Nueva York: Psychology Press.

\section{Diccionarios y vocabularios}

Abreu, João Capistrano de (1914). Rã-txa hu-ni-ku-ĩ: a lingua dos Caxinauás do rio Ibuaçú, affluente do Murú. Rio de Janeiro: Typographia Leuzinger. 
Alemany, Agustín (1927 [1908]). Castellano-shipibo y elementos de gramática. En Bernardino Izaguirre (editor). Historia de las misiones franciscanas en el oriente del Perú, vol. 13, pp. 283-348. Lima: ArguedasMedalla.

Anónimo (1927). Diccionario cunibo-castellano y castellano-cunibo. En Bernardino Izaguirre (editor). Historia de las misiones franciscanas en el oriente del Perú, vol. 13, pp. 391-474. Lima: Arguedas-Medalla.

Beekes, Robert (2010). Etymological dictionary of Greek, vol. I-II. Leiden: Brill.

Castelnau, Francis de (1851). Appendice: Vocabulaires des Langues Indiennes. En Expédition dans les Parties Centrales de l'Amérique du Sud, Tomo 5, pp. 249-302. Paris: P. Bertrand, Libraire-Éditeur.

Corominas, Joan (1987 [1973]). Breve diccionario etimológico de la lengua castellana. Tercera edición. Madrid: Gredos.

d'Ans, André Marcel (1972). Léxico yaminahua. Centro de Investigación de Lingüística Aplicada. Documento de trabajo $\mathrm{N}^{\circ} 1$.

de Vaan, Michiel (2008). Etymological dictionary of Latin and the other Italic languages. Leiden: Brill.

Fleck, David W.; Uaquí, Fernando; Jiménez, Daniel (2012). Diccionario matsés-castellano. Iquitos: Tierra Nueva.

Hart, Helen (1988). Diccionario chayahuita-castellano. Lima: SIL. https://www.sil.org/system/files/ reapdata/53/83/82/53838289028662789570876716126619509316/slp29.pdf

Hyde, Sylvia (1980). Diccionario amahuaca. Yarinacocha: SIL. https://www.sil.org/system/files/ reapdata/75/51/06/75510632626727367137560905769008297474/slp07.pdf

Kindberg, Lee (1980). Diccionario asháninca. Yarinacocha: SIL. https://www.sil.org/system/files/ reapdata/15/05/87/150587103864951424705632321744367293106/dt19.pdf

Leslau, Wolf (1963). Etymological dictionary of Harari. Berkeley: University of California Press.

Lewis, Charlton T. (1984 [1879]). A Latin dictionary founded on Andrews'Edition of Freund's Latin Dictionary. New York: Oxford University Press.

Loos, Eugene; Loos, Betty (1998). Diccionario capanahua-castellano. Lima: sIL. https://www.sil.org/system/ files/reapdata/79/70/27/79702734483539789805867360231211106713/slp45.pdf

Loriot, James; Lauriault, Erwin; Day, Dwight (1993). Diccionario shipibo-castellano. Lima:SIL. https://www.sil. org/system/files/reapdata/28/10/70/28107082976791018432371168218236399036/slp31.pdf

Martius, Carl F. P. (1863). Glossaria linguarum brasiliensium. Glossarios de diversas lingoas e dialectos, que fallao os indios no imperio do Brazil. Erlangen: Druck von Junge \& Sohn.

Montag, Susan (1981). Diccionario cashinahua. Yarinacocha: SIL. https://www.sil.org/system/files/ reapdata/11/98/57/119857554235813427595875320394596487807/slp09.pdf

Navarro, Manuel (1903). Vocabulario castellano-quechua-pano con sus respectivas gramáticas quechua y pana. Lima: Imprenta del Estado. 


\section{CAJAVILCA - CUESTIONES ETIMOLÓGICAS DEL ALMA ORIGINARIA}

Orel, Vladimir E.; Stolbova, Olga V. (1995). Hamito-Semitic etymological dictionary. Materials for a reconstruction. Leiden: Brill.

Payne, David (1980). Diccionario ashéninca-castellano. Lima: sIL. https://www.sil.org/system/files/ reapdata/27/59/65/27596502782406212904632085133341587136/dt18.pdf

Rivet, Paul; Tastevin, Constant (1932). Les dialectes pano du haut Juruá et du haut Purus. Acts of the Xxth International Congress of Americanists, vol. 3, pp. 227-278. Rio de Janeiro: Imprensa Nacional.

Ruiz de Montoya, Antonio (1876). Vocabulario y tesoro de la lengua guaraní o más bien tupí, I-II. Viena: Faesy y Frick.

Scott, Marie (2004). Vocabulario sharanahua-castellano. Lima: siL. https://www.sil.org/system/files/ reapdata/47/59/02/47590263786118801315692283845351430890/slp53.pdf

Schuessler, Axel (2007). ABC Etymological Dictionary of Old Chinese. Honolulu: University of Hawai'i Press.

Shell, Olive (1987). Vocabulario cashibo-cacataibo. Lima: siL. https://www.sil.org/system/files/ reapdata/76/23/85/76238545770735431946881370844869562106/slp23.pdf

Siméon, Rémi (1992). Diccionario de la lengua náhuatl o mexicana. Novena edición. Ciudad de México: Siglo Veintiuno.

Starostin, Sergei; Dybo, Anna; Mudrak, Oleg (2003). Etymological dictionary of the Altaic Languages. Boston: Brill.

Steinen, Karl von den (1904). Diccionario sipibo. Castellano-deutsch-sipibo. Berlin: Dietrich Reiner.

Valenzuela, Pilar (2013). Diccionario shiwilu-castellano, castellano-shiwilu. Lima: Federación de Comunidades Nativas de Jeberos.

Zariquiey, Roberto (2016). Vocabulario iskonawa-castellano-inglés. Medford: Department of Romance Languages, Tufts University. 


\section{Abreviaturas de diccionarios}

ABR Abreu, 1914

ALE Alemany (en Izaguirre, 1927)

ANO Anónimo (en Izaguirre, 1927)

CAS Castelnau, 1851

DAN d'Ans, 1972

FLE Fleck et al., 2012

HYD Hyde, 1980

LOO Loos \& Loos, 1998

LOR Loriot et al., 1993

MON Montag, 1981

NAV Navarro, 1903

SCO Scott, 2004

SHE Shell, 1987

STE Steinen, 1904

ZAR Zariquiey, 2016

Recebido: $12 / 6 / 2018$

Versão revista 1: 16/10/2018

Versão revista 2: 25/12/2018

Aceito: 9/01/2019 